\title{
Contextos de influências atuantes no desenvolvimento da profissionalidade e do profissionalismo dos professores
}

\author{
Influences contexts for the development of professionals and professionalism \\ Contextos de influencias acuerdos en el desarrollo de la profesionalidad \\ $y$ del profesional de los profesores
}

CRISLAINY DE LIRA GoNÇALVES ${ }^{1} 1$

LuCINALVA ANDRADE ATAIDE DE ALMEIDA@1

${ }^{1}$ Universidade Federal de Pernambuco (UFPE), Caruaru, PE, Brasil.

\begin{abstract}
$\diamond$
\section{RESUMO}

Este trabalho parte do entendimento de que a profissionalidade e o profissionalismo dos professores não se desenvolvem de forma homogênea, mas estão condicionados a diversos elementos que fazem parte de seus contextos pessoais, formativos e profissionais. Nesse sentido, objetivamos analisar os contextos que influenciam no desenvolvimento da profissionalidade e do profissionalismo dos professores. Nossas análises foram subsidiadas pela perspectiva teóricometodológica da análise do discurso (ORLANDI, 2005; 2012) e do Ciclo de Políticas (BALL, 2011), e tiveram por foco relacionar elementos apontados pela literatura como sendo fundantes para o delineamento da profissionalidade e do profissionalismo dos sujeitos a partir de suas pessoalidades.
\end{abstract}

Palavras-chave: Contextos de influência. Profissionalidade. Profissionalismo.

\begin{abstract}
This work is based on the understanding that the professionality and professionalism of teachers do not develop in a homogeneous way, but they are conditioned to several elements that are part of their personal, educational and professional contexts. In this sense, we aim to analyze the contexts that influence the development of professionality and professionalism of teachers. Our analyzes were subsidized by the theoretical-methodological perspective of the discourse analysis (ORLANDI, 2005; 2012) and the Policy Cycle (BALL, 2011), and were aimed at relating elements pointed out in the literature as foundations for the delineation of the professionality and professionalism of the subjects from their personalities.
\end{abstract}

Keywords: Contexts of influence. Professionality. Professionalism.

\section{RESUMEN}

Este trabajo parte del entendimiento de que la profesionalidad y profesionalismo de los profesores no se desarrollan de forma homogénea, sino que están condicionadas a diversos elementos que forman parte de sus contextos personales, formativos y profesionales. En este sentido, objetivamos analizar los contextos que influencian en el desarrollo de la profesionalidad y del profesionalismo de los profesores. Los análisis fueron subsidiados por la perspectiva teórico-metodológica del análisis del Discurso (ORLANDI, 2005; 2012) y del Ciclo de Políticas (BALL, 2011), y tuvieron por foco relacionar elementos apuntados por la literatura como siendo fundantes para el delineamiento de la profesionalidad y profesionalismo de los profesionales sujetos a su personalidad.

Palabras clave: Contextos de influencia. Profesionalidad. Profesionalismo. 


\section{INTRODUÇÃO}

A docência se constituiu historicamente enquanto grupo heterogêneo, seja devido às próprias divisões do trabalho ocorridas no seio da profissão, seja pela hierarquia social que estas divisões e suas especificidades representam, sendo fomentadas diariamente pela mídia e pelos sistemas de avaliação que vêm atribuindo ao trabalho dos professores a responsabilidade sobre o sucesso ou insucesso de seus alunos, seja na educação básica ou ainda na educação superior, o que faz com que os professores (com diferentes níveis de formação e atuantes em diferentes níveis de ensino) tenham sua profissionalidade aferida pelos resultados de exames externos, resultando na desigualdade de direitos profissionais, mesmo entre membros de um mesmo grupo profissional.

Pensando, assim, na multiplicidade de sentidos que a heterogeneidade de sujeitos e perfis profissionais representa para o processo de profissionalização da docência, e considerando que atreladas às diferenças formativas estão as diferenças pessoais, ou seja, a particularidade de cada sujeito, objetivamos através deste trabalho analisar os contextos que influenciam no desenvolvimento da profissionalidade e do profissionalismo dos professores. Para tanto, de antemão sinalizamos que a nossa compreensão acerca do conceito de profissionalidade e de profissionalismo se dá no âmbito das discussões da profissionalização enquanto processo.

Entendemos a profissionalização a partir de uma duplicidade de sentidos que são mutuamente interdependentes, isto porque "a profissionalização encontra-se associada ao projeto ou processo político ou social (ou ainda individual) através do qual uma determinada ocupação (ou indivíduo) procura reconhecimento como profissão (ou como profissional)" (FLORES, 2014, p. 855). Deste modo, a profissionalização se dá tanto na esfera individual (formativa profissional), como na esfera coletiva (política, social e profissional).

Frente a essas considerações, destacamos que a profissionalização é um processo político, social e individual, sendo estes descritores indissociáveis. Assim, ao buscarem um curso superior que os habilite a exercer a função de professores, os futuros profissionais estão buscando se profissionalizar em determinada área, neste caso, a docência. Porém, enquanto adquirem este nível que os profissionaliza e os habilita como profissionais, os estudantes - diferentemente de outras profissões que possuem um status elevado - se veem imersos em um outro processo de profissionalização que se dá em um nível macro e coletivo, e que busca legitimar o prestígio social da profissão frente às demais profissões e à sociedade.

Deste modo, durante a formação inicial, os estudantes se profissionalizam enquanto indivíduos e, concomitantemente, inserem-se em um processo de luta pela profissionalização em uma esfera coletiva. Nesse sentido, a formação promove o movimento entre as aspirações individuais e as aspirações coletivas, ao mesmo tempo em que unifica através desse movimento o caráter político, social e individual. Assim, indivíduo e ocupação procuram ao mesmo tempo a elevação de seu status ao de profissional, sendo isto, como já reportamos, a realidade de profissões como a docência, que estão a galgar maior reconhecimento no rol das profissões.

Monteiro (2015, p. 39) clarifica a compreensão acerca da profissionalização individual e coletiva afirmando que "coletivamente, profissionalização é o processo através do qual uma profissão eleva o seu grau de profissionalidade" e, individualmente, "profissionalização é o processo de aprendizagem e de socialização profissionais, isto é, tanto de aquisição de saberes como de interiorização de valores [...]". Logo, pensar a formação e atuação profissional de professores na atualidade consiste em levar em consideração estes dois âmbitos da profissionalização, sabendo que, embora possuam características e objetivos específicos, eles se complementam, visto que todo coletivo parte de um fazer individual.

Assim, a profissionalização coletiva é impulsionada pela profissionalização individual, pelos saberes apreendidos na formação e pelas práticas cotidianas que se desenvolvem nas salas de aula e que são muitas vezes invisibilizadas. Do mesmo modo, o individual se ancora em uma construção coletiva, visto que ao profissionalizarse através de um curso superior o estudante internaliza aprendizagens que foram construídas coletivamente entre alunos e professores, como também estão em um curso que desenvolve um currículo que foi pensado no coletivo que, por sua vez, é fruto de uma política de formação que foi pensada, negociada e incorporada pelo contexto da prática através da unificação do trabalho e dos conhecimentos de inúmeros sujeitos. Frente a isto, salientamos que as profissionalizações pelas quais os estudantes passam a ter contato na formação inicial não são independentes. Nesse sentido, o processo de profissionalização, que é coletivo e ao mesmo tempo individual, coloca os sujeitos em posições discursivas diferentes, que correspondem a diferentes formações discursivas (ORLANDI, 2012) que se configuram pelas relações estabelecidas com a ideologia.

Sendo assim, os discursos profissionais emitidos pelos professores através de vários veículos (como a fala, a prática, os gestos, os silêncios, entre outros) relacionam-se ao processo de profissionalização em que estão inseridos e, as profissionalizações, tanto em nível individual quanto em nível coletivo, fundem-se, visando o desenvolvimento de competências profissionais, devendo assim "promover, em simultâneo, a apropriação de uma 
dada cultura profissional por parte dos formandos e favorecer a construção da sua identidade profissional, construção essa que irá prolongar-se ao longo da sua vida profissional" (MORGADO, 2011, p. 796, grifos do autor).

Sendo, assim, a identidade uma construção pessoal, oriunda da história de vida dos sujeitos, refletimos o quanto esta construção identitária pode favorecer não apenas no percurso e consolidação do processo individual de profissionalização, como também no processo coletivo. Nesse sentido, ao conceituar a profissionalização, Monteiro (2015) lança mão desta relação entre a construção de si enquanto profissional e do coletivo ocupacional. Para tanto, define a profissionalização como "um processo através do qual uma profissão é construída pelos que a exercem, coletivamente e como forma de realização pessoal" (2015, p. 15), sendo ainda, segundo o autor, uma construção que se realiza através de relações interprofissionais e intraprofissionais.

Sendo a profissionalização um processo individualcoletivo, constituída pelo imbricamento entre as relações inter e intraprofissionais, que abarcam características e contextos do grupo profissional e das experiências pessoais dos sujeitos, compreendemos que mesmo em um processo mais amplo de profissionalização, a subjetividade dos sujeitos, suas experiências e as identidades que constroem e reconstroem durante sua formação e percurso profissional tornam-se instrumentos significativos de influência. Nesse sentido é que ressaltamos a importância das biografias profissionais, porém, não apenas elas, mas a biografia dos sujeitos enquanto seres sociais que, para constituírem-se profissionalmente, passaram por experiências de vida que influenciaram ou até mesmo determinaram seus percursos e escolhas profissionais.

Frente a esta relação com o percurso e a historicidade do sujeito, salientamos que "[...] o que define o sujeito é o lugar do qual ele fala em relação aos diferentes lugares de uma formação social" (ORLANDI, 2005, p. 146), sendo esta formação social determinante não apenas para designar o lugar dos sujeitos, mas também aquilo que ele diz e faz, direcionando a ação dos sujeitos a algo que se espera que ele faça, dado o seu lugar discursivo. Deste modo, as várias posições do sujeito podem representar diferentes formações discursivas, que determinam o que pode e o que deve ser dito em dado momento. Isto indica que o sujeito se constitui a partir de várias posições que, por sua vez, orientam em que direção se encaminhará seus discursos. Nesse sentido, Orlandi (2012) faz alusão aos pontos de entrada e de fuga que acompanham os sujeitos, afirmando que enquanto os pontos de entrada correspondem a múltiplas posições do sujeito, "os pontos de fuga são as diferentes perspectivas de atribuição de sentidos: ao relacionar-se com os vários pontos de entrada, o leitor pode produzir leituras que se encaminham em várias direções" (2012, p. 153).

Partimos, assim, da compreensão de que os sujeitos, a depender dos seus pontos de entrada, que dizem respeito à posição que ocupam, encontram na produção de sentidos pontos de fuga que os encaminham a outras direções. Nesta lógica, entendemos que os professores, ao adentrarem o percurso profissional a partir de suas várias posições discursivas, produzem, em meio a tantas perspectivas, sentidos sobre a docência e sobre as práticas cotidianas. Nesse ínterim, ao produzirem sentidos, os sujeitos encontram pontos de fuga, ou seja, que se relacionam ao percurso dinâmico de suas historicidades (ORLANDI, 2012) e que apontam que a formação dos sujeitos é pessoal, institucional e profissional (NÓVOA, 2009). Nesta imbricação de contextos que coexistem enquanto identidade dos sujeitos, destacamos a profissionalidade e o profissionalismo enquanto dimensões estruturantes do fazer profissional dos professores.

\section{Profissionalidade e PROFISSIONALISMO: O MOVIMENTO INTERNO E EXTERNO ENTRE OS SABERES E AS PRÁticAS PROFISSIONAIS}

Ao tratar a profissionalidade e o profissionalismo enquanto dimensões ou elementos constituintes e caracterizadores de uma profissão ou de um grupo profissional que está a profissionalizar-se, compreendemos que essas duas dimensões, embora coexistam a partir de uma relação de interdependência, possuem especificidades. Roldão (2007, p.96), por exemplo, aponta a profissionalidade docente como um elemento interno ou intrínseco à profissão, enquanto o profissionalismo, é abordado por essa mesma autora como um elemento externo ou extrínseco.

Os elementos internos, ou seja, a profissionalidade, são associados e caracterizados pela "posse de determinado saber distintivo: a afirmação de um conhecimento profissional especifico" (Ibidem, grifos da autora), enquanto os elementos extrínsecos ou externos da profissão docente são, segundo a autora, de natureza políticoorganizativa, e estão relacionados à "institucionalização da escola como organização pública, e do currículo que a legitima no plano social" (Ibidem, grifos da autora). Desta feita, compreendemos que a profissionalidade remete ao plano dos saberes em um âmbito local, entendido como o campo de atuação prática, sendo estes saberes diversos e plurais, enquanto o profissionalismo, embora não se distancie desta mesma lógica dos saberes, está relacionado a objetivos mais amplos que um grupo ocupacional pretende alcançar, seja no cenário social ou na própria estrutura organizacional das profissões em geral. 
Para melhor explicitarmos as definições que têm respaldado as discussões acerca da profissionalidade e do profissionalismo, propomos uma análise conceitual de ambas as dimensões, iniciando pela profissionalidade. Morgado (2011), afirma que a construção da profissionalidade docente ocorre "de forma progressiva e contínua, baseia-se no desenvolvimento de competências e da identidade profissional, inicia-se na formação e prolonga-se ao longo de toda a carreira" (2011, p. 799). Assim, como já destacamos, a profissionalidade consiste em movimento entre os saberes práticos e teóricos, que fundamentam a ação do professor no exercício de sua profissão.

Nesse movimento dos saberes, compreendemos a partir da referida contribuição de Morgado que os saberes que são adquiridos na formação não estão isolados ou tampouco estagnados. Pelo contrário, eles tendem a evoluir, modificar-se, adaptar-se, incorporar-se a outros saberes, formando, por conseguinte, novos saberes que são forjados a partir da realidade que compõe o contexto prático de atuação dos professores. Desse modo, a profissionalidade expressa o agir docente, baseado em conhecimentos apreendidos e legitimados na formação e no desenvolvimento da profissão (BOING, 2002). Assim, a profissionalidade distingue os profissionais ou membros de uma ocupação que está a se profissionalizar ou ainda a legitimar a importância social de seus serviços. Nesta perspectiva, para Roldão (2005), a profissionalidade consiste em um "conjunto de atributos, socialmente construídos, que permitem distinguir uma profissão de outros muitos tipos de actividades, igualmente relevantes e valiosas" (2005, p. 108, grifo da autora).

Essa distinção da docência dentre tantos outros grupos ocupacionais se dá pelos saberes que este grupo ocupacional detém. Para Boing (2002), é por meio da profissionalidade que o professorado adquire "os conhecimentos necessários ao desempenho de suas atividades docentes e adquirem os saberes próprios de sua profissão: os saberes das disciplinas, do currículo, da experiência, enfim, os saberes pedagógicos em geral" (2002, p. 6). Deste modo, a profissionalidade, por envolver estes vários saberes, dentre eles, os saberes da experiência, também pode ser entendida enquanto conjunto de saberes que subsidiam o desenvolvimento profissional.

Desta feita, salientamos que os saberes teóricopráticos que embasam as práticas cotidianas e fundamentam o desenvolvimento profissional não são os únicos descritores daquilo que de fato podemos compreender por profissionalidade. Roldão (2007) descreve elementos outros que a caracterizam, sendo eles: a) o reconhecimento social da especificidade da função; b) o saber específico; c) o poder de decisão sobre o trabalho desenvolvido e responsabilização social e pública pela mesma, o que remete ao controle e autonomia sobre a atividade desenvolvida; e d) a pertença a um corpo coletivo. Embora os saberes não sejam os únicos fatores constituintes da profissionalidade docente, nota-se que eles perpassam todos os descritores, visto que a especificidade da função, o poder de decisão e a pertença a um corpo coletivo são práticas profissionais que remetem à vivência dos saberes teórico-práticos.

Em suma, poderíamos definir a profissionalidade como a "afirmação do que é específico na ação docente, isto é, o conjunto de comportamentos, destrezas, atitudes e valores que constituem a especificidade de ser professor" (SACRISTÁN, 1999, p. 65), o que evidencia que a profissionalidade se manifesta nas muitas práticas desenvolvidas pelos professores em seus cotidianos, como por exemplo, planejar, ensinar, selecionar os conteúdos do currículo, organizar o espaço da sala de aula, avaliar os alunos, avaliar-se, refletir, considerar tempo curricular, interagir com os pais etc.

Ao pensarmos nas práticas cotidianas dos professores, entendendo-as como manifestações da profissionalidade, logo percebemos que a mesma pode ser definida como a observância de determinadas regras baseadas em um conjunto de saberes. Porém, vale salientar que essas regras nem sempre são muito precisas, estando sujeitas a uma reelaboração pelos professores (a depender do contexto que estão inseridos e das demandas com que se deparam em seus cotidianos), o que mais uma vez reforça a ideia de profissionalidade enquanto movimento, processo, progressão que não se dá de modo isolado, mas que está articulada a outras dimensões da profissionalização. Sendo assim, após traçarmos considerações sobre o aspecto interno à profissão, iremos a partir deste ponto tratar do elemento mais externo à profissão, ou seja, o profissionalismo.

Gonçalves (2007) considera que "os componentes mais importantes do conceito de profissionalismo seriam o controle sobre o trabalho, a capacidade de definição dos problemas e o papel central da educação" (2007, p. 129), sendo que todas estas ações requerem o uso de saberes específicos, seja para identificar os problemas sociais que circundam o campo de atuação da ocupação, seja para definir os problemas que estão no âmbito de sua competência e jurisdição. Isto envolve não apenas o poder na resolução de problemas, como o controle sobre o próprio trabalho, não só no sentido das relações internas entre os membros, como também no sentido da regulação do acesso à ocupação. Em síntese, o que estamos buscando enfatizar é que o profissionalismo envolve o controle, o monopólio e a autonomia das práticas, sendo que esses elementos exigem a apropriação e uso dos saberes específicos. 
Nesse sentido, Contreras (2002, p. 68) afirma que,

[...] devemos considerar o profissionalismo fundamentalmente como um movimento de autodefesa corporativa de certas ocupações que tiveram a possibilidade de justificar tal postura na posse de um conhecimento especializado e exclusivo.

A partir desta declaração, compreendemos o profissionalismo em seu caráter coletivo, não se restringindo a ações específicas ou meramente valorativas de determinados membros de uma ocupação, mas, relacionando-se, em um sentido amplo, às ações coletivas e corporativas, marcando a identidade profissional de um grupo a partir da deontologia profissional que ele professa seguir e ao mesmo tempo, defende.

Nesse mesmo sentido Monteiro (2015), afirma que o

[...] profissionalismo significa o exercício de uma profissão de acordo com o seu conteúdo identitário. As suas coordenadas são os graus de especialização e de exigência deontológica da profissão, tendo como bissetriz as qualidades dos seus profissionais (MONTEIRO, 2015, p. 34).

As palavras de Monteiro aludem à ideia de que são as ações e qualidades profissionais individuais que compõem o caráter corporativo do profissionalismo, visto que o individual e o coletivo constituem-se dialogicamente. Assim, o autor ainda afirma que o

Profissionalismo não significa apenas, portanto, fazer bem o que se faz, significação meramente instrumental cujo o critério é a eficácia. Significa também fazer bem aquilo que se sabe e se pode fazer, significação que lhe acrescenta a dimensão normativa, da ordem da licitude e da eticidade. A súmula do profissionalismo está na unidade de ciência, consciência e excelência (MONTEIRO, 2015, p. 34).

Essas palavras nos remetem ao entendimento de que não basta aos membros de uma ocupação fazerem bem o que sabem, se, ao mesmo tempo, não possuem o poder de fazê-lo. Daí a importância de uma organização ocupacional coletiva que proteja os direitos do grupo, promova a proteção de seu monopólio e garanta a autonomia, ou seja, o poder fazer, pois, como afirma Freidson (1998), "somente quando um grupo se torna efetivamente organizado é que uma ocupação pode conquistar para seus membros um pouco de autonomia para o controle alheio" (1998, p. 114).

O profissionalismo se apresenta como peça central nesse processo de organização ocupacional e busca por maior autonomia, sendo a autoridade do conhecimento profissional e a orientação intelectual decisivas para a diferenciação entre as profissões. Retomando as palavras de Monteiro (2015), poderíamos associar a ideia de que o profissionalismo, em suma, pode caracterizar-se pela ciência, consciência e excelência profissional exercidas pelos membros de uma ocupação. Não obstante, também compreendemos que todos estes elementos aqui apresentados e que constituem e caracterizam o profissionalismo estão sujeitos a variações, isto porque as profissões se diferenciam por inúmeros fatores, como o nível de especialização, e também pelo ambiente de trabalho. Acreditamos ainda que estas variações se deem não somente entre ocupações distintas, mas também entre membros que participam de uma mesma ocupação.

Nesse sentido, salientamos que o profissionalismo e a profissionalidade de membros que ocupam a mesma função em determinado grupo ocupacional não se desenvolvem a partir de um padrão específico. Pelo contrário, nesse desenvolvimento devem ser levados em consideração os aspectos de variação apontados por Freidson, como o nível de especialização e o ambiente de trabalho, mas, não apenas isso. Em outros estudos (NÓVOA, 2009; FLORES, 2014), nota-se que o desenvolvimento profissional está também relacionado às experiências individuais dos sujeitos, a aspectos e experiências de sua formação, às exigências a que estão submetidos, como também às políticas de formação e às políticas que embasam as regras e demandas de seu trabalho cotidiano. Desta feita, percebemos a necessidade de compreender a profissionalidade e o profissionalismo enquanto conceitos que estão em desenvolvimento e, ao mesmo tempo, em um movimento que é conduzido pela individualidade dos sujeitos e contextos.

\section{CONTEXTOS DE INFLUÊNCIAS QUE PERPASSAM A PESSOALIDADE E O DESENVOLVIMENTO DA PROFISSIONALIDADE E PROFISSIONALISMO DOS PROFESSORES}

Ao tratar da profissionalidade e do profissionalismo especificamente no âmbito da docência, percebemos que essas dimensões estão condicionadas a influências diversas que podem interferir de modo positivo ou não na prática e desenvolvimento profissional dos professores. Partindo da compreensão de que a profissionalidade e o profissionalismo orientam o processo de profissionalização de uma ocupação, logo surge a necessidade de se compreender os contextos de influência que circundam os professores em suas práticas cotidianas, isto porque, como afirma Veiga (1999), "o discurso da profissionalização, descolado da análise contextual do trabalho docente, pode ser uma forma de escamotear as verdadeiras exigências de reconstrução do trabalho do professor (1999, p. 143). Assim, considerando esta 
necessidade de se conhecer e analisar contextualmente o trabalho docente, desenvolveremos neste tópico uma breve análise descritiva dos contextos que influenciam a profissionalidade, o profissionalismo e consequentemente o desenvolvimento profissional dos professores.

Um primeiro ponto que destacamos, diz respeito ao contexto histórico em que se propõe uma análise do que seria o desenvolvimento da profissionalidade e do profissionalismo em um dado contexto físico, e, também ideológico, pois, como afirma Sacristán (1999), o conceito de profissionalidade "está em permanente elaboração, devendo ser analisado em função do momento histórico concreto e da realidade social que o conhecimento escolar pretende legitimar; em suma, tem de ser contextualizado" (1999, p. 65).

Nesse sentido, ao tratarmos os conceitos de profissionalidade e de profissionalismo, torna-se imprescindível focalizar os sentidos que esses conceitos podem ter adquirido ao longo da história, isto porque "o sentido não existe em si, mas é determinado pelas posições ideológicas colocadas em jogo no processo sócio-histórico em que as palavras são produzidas (ORLANDI, 2005, p.42). Assim, para compreendermos os sentidos que circundam os termos, precisamos considerar as posições ideológicas que os fundamentam e contribuem para a constituição dos sentidos.

Um exemplo disto consiste nas mudanças que marcaram historicamente o termo profissionalidade, que, segundo Barisi (1982) se originou nas lutas operárias da Itália e desempenhava um papel tanto estratégico (quando através da criação de coletivos os trabalhadores reivindicavam direitos e mudanças estruturais relacionadas a aspectos externos e mais gerais do trabalho) quanto tático (à medida que os trabalhadores modificavam a partir de seus saberes a organização interna de seu trabalho). Assim, nesse contexto histórico, a profissionalidade adquiriu o sentido de unificadora da classe operária, tornando-se um importante instrumento na luta pela modificação da estrutura e da organização do trabalho. Barisi (1982) ainda afirma que a própria noção de profissionalidade foi adquirindo sentidos diferenciados, sofrendo modificações provocadas por mudanças econômicas, políticas, entre outras. Logo, a partir desse exemplo percebemos a constante reelaboração dos conceitos e a não estagnação dos sentidos que lhes são atribuídos, como também percebemos os efeitos do contexto histórico sobre a elaboração destes sentidos.

Veiga (1999), ao definir o conceito de profissionalidade faz alusão à figura do professor enquanto um sujeito histórico, que exerce uma tarefa ou profissão dentro de um dado contexto. Assim, para a autora, a conceituação da profissionalidade contempla em grande medida a subjetividade do professor, que está inserida em contexto não apenas histórico, mas sobretudo ideológico de significação que o faz exercer a docência de um modo específico e que corresponde àquele dado contexto.

É interessante destacar ainda nas palavras de Veiga a alusão que a autora faz à subjetividade do sujeito enquanto uma condicionante no direcionamento e desenvolvimento da profissionalidade e do profissionalismo docente. Isto porque, mesmo que o contexto histórico/ideológico influencie na formação de sentidos e consequentemente das práticas desenvolvidas pelos professores, vale salientar que a história e a ideologia não afetam de modo homogêneo a produção de sentidos pelos sujeitos, visto que cada sujeito passou por experiências distintas ou até mesmo guarda memórias diferentes que estão circunscritas na história.

Este é um segundo ponto por nós destacado em nossa tentativa de elencar possíveis influenciadores do desenvolvimento profissional, ou seja, os intrínsecos ao sujeito, e que se relacionam com sua história de vida, suas experiências pessoais, familiares, formativas, profissionais, entre outras. Aspectos que dizem respeito à identidade pessoal e profissional de cada sujeito e que têm a ver com a subjetividade que cada um traz consigo. Assim, coadunamos com Nóvoa (2009), que afirma que a profissionalidade docente se constrói no interior de uma pessoalidade do professor, não podendo deixar de ser considerada esta dimensão na análise da profissionalidade e, acrescentaríamos ainda, do profissionalismo, visto que estas dimensões coexistem mutuamente constituindo um processo maior, ou seja, o processo de profissionalização.

Desse modo, ao pensar a pessoalidade dos professores, logo nos remetemos à identidade desses e salientamos que essas identidades (individual-coletiva), embora específicas, se relacionam mutuamente. Ao tratar sobre a identidade profissional, por exemplo, Flores $(2014$, p. 853) argumenta que esta define nos professores: "quem são, a imagem que têm de si próprios, os sentidos que atribuem ao seu trabalho e a si próprios enquanto professores e os significados que os outros lhes atribuem", o que torna, portanto, a identidade uma construção pessoal, mas também relacionada ao meio de influências em que o sujeito vive, possuindo aspectos intra e interpessoais. Deste modo, salientamos que a identidade incorporada pelos professores reverbera na forma como estes direcionam o seu saber-fazer, como também impulsiona o desenvolvimento de práticas mais autônomas e embasadas pelo poder profissional.

Contudo, apesar da identidade ser construída a partir desta relação/tensão entre os contextos pessoais e os demais contextos de influência presentes no campo de atuação profissional, vale salientar que ela não está acabada, estando, pelo contrário, sujeita às mesmas e outras influências que podem trazer sentidos novos à 
identidade do professor e consequentemente à sua prática. Nesta perspectiva, ressaltamos a partir das considerações de Flores que a identidade dos professores depende de uma variedade de fatores, tais como:

[...] da forma como se relacionam com seus alunos, da disciplina que ensinam, dos papéis que desempenham, dos contextos em que trabalham, do quadro social e cultural mais amplo em que o ensino se inscreve, da sua biografia, das oportunidades de aprendizagem e de desenvolvimento profissional no local de trabalho, do apoio etc. (FLORES, 2014, p. 853).

Logo, as identidades profissionais, que auxiliam no processo de desenvolvimento da profissionalidade e do profissionalismo estão intimamente associadas a aspectos da organização do trabalho realizada pelas instituições de ensino e demais órgãos de controle, como por exemplo as secretarias de educação e os programas por elas adotados. Essas mesmas identidades se relacionam a aspectos mais individuais dos professores, como por exemplo sua biografia, o que reforça a ideia de Nóvoa (2009), de que "no ensino as dimensões profissionais cruzam-se sempre, inevitavelmente com as dimensões pessoais" (2009, p.31), não havendo separação entre estas dimensões, visto que o profissional só pode existir subsidiado pelos aspectos pessoais.

Umoutro aspecto pornós destacado, eque interfere tanto na produção das identidades como no desenvolvimento da profissionalidade e do profissionalismo dos professores, diz respeito ao ambiente de trabalho em que atuam. Assim, o ambiente de trabalho, que está relacionado tanto a aspectos físicos quanto relacionais de uma instituição, contribui positivamente ou não para o desenvolvimento profissional dos professores. Nesse sentido, Alves e André (2013), ao tratarem do aspecto organizacional das instituições de ensino afirmam que

O ambiente de trabalho dos professores, expresso nas relações que configuram o clima organizacional da instituição, tanto pode oferecer aos professores um contexto com o poder de aprisionar, conformar e dificultar o desenvolvimento das condições de produção dos descritores de profissionalidade, quanto pode apoiar, estimular e subsidiar a sua constituição (ALVES; ANDRÉ, 2013, p. 14).

Nessa mesma linha de raciocínio Tardif; Lessard (2005, p.55) também ressaltam que a "escola possui algumas características organizacionais e sociais que influenciam o trabalho dos agentes escolares" não se limitando aos espaços físicos, mas ampliando-se à interação dos agentes escolares no que concerne às demandas do cotidiano escolar. Porém, esses autores também tecem considerações sobre os aspectos físicos e materiais da organização escolar, argumentando que "a falta de recursos e de tempo e a escassez de instrumentos pedagógicos são fatores 'materiais' frequentemente mencionados pelos professores como estando entre as maiores dificuldades dessa profissão" (2005, p. 55), visto que para o desenvolvimento de atividades diversificadas, inovadoras e condizentes com os avanços tecnológicos faz-se necessário que o professor possua, como pontuam os autores, tempo e materiais específicos para a consolidação de tais atividades.

Atender, assim, à variedade de necessidade e ritmos de aprendizagem dos alunos, muitas vezes sem recursos que auxiliem os professores, torna-se uma tarefa difícil de ser realizada quando o professor não tem ao menos o mínimo de suporte. Essa precarização do trabalho docente pode afetar o desempenho profissional dos professores, fazendo com que sua função específica, que segundo Roldão (2005), consiste em ensinar e, consequentemente, garantir a aprendizagem dos alunos, seja colocada em cheque, visto que a falta de recursos, em muitos casos, pode limitar as diferentes estratégias de ensino que os professores, porventura, poderiam utilizar.

Ao tratar do aspecto do ambiente profissional dos professores enquanto um dos mais importantes constituintes de suas identidades, Lüdke e Boing (2004) questionam em seus estudos se, e como, a precarização do trabalho docente pode estar repercutindo sobre a construção da identidade dos professores, sendo que as identidades, que configuram o aspecto pessoal dos mesmos, relacionam-se intimamente com o profissional, pois como afirma Nóvoa (2009), não se pode falar em profissionalidade - e ligada a esta, acrescentamos o profissionalismo -, desconsiderando a pessoalidade dos sujeitos.

Núñez e Ramalho (2008) associam a identidade da docência também como parte do processo de profissionalização, visto que está relacionada às representações dos professores sobre si. Sendo assim, a identidade que os professores possuem direcionam suas práticas profissionais e o desenvolvimento da profissionalidade e profissionalismo através dos saberesfazeres que desenvolvem cotidianamente.

Um outro fator de influência sobre a profissionalidade e o profissionalismo dos professores, e que consideramos imprescindível destacar, diz respeito às influências dos contextos políticos que estão presentes nas escolas, seja através das práticas apreendidas na formação, seja através das políticas de currículo e de avaliação, ou até mesmo de decisões políticas que advêm da esfera organizativa de educação em que a escola se insere.

Para abordar os contextos políticos tomamos por base teórica as considerações de Ball (2001) e Ball; Mainardes (2011), que tratam das políticas educacionais a partir do imbricamento entre diversos contextos de influência. 
Os autores apresentam que a formação das políticas educacionais se dá a partir do contexto de influências, do contexto do texto e do contexto da prática. $\mathrm{O}$ primeiro destes contextos é o contexto de influências, que é descrito por Lopes e Macedo (2011) como

[...] o território em que são hegemonizados os conceitos mais centrais da política, criando-se um discurso e uma terminologia próprios que visam a legitimar a intervenção. Neste contexto, são estabelecidos os princípios básicos que orientam as políticas, em meio a lutas de poder nas quais os autores são desde partidos políticos, esferas do governo a grupos privados e agências multilaterais, como comunidades disciplinares e institucionais e sujeitos envolvidos na propagação de ideias oriundas de intercâmbios diversos. Como os interesses desses diferentes atores são muitas vezes conflitantes, trata-se de um contexto complexo de luta por hegemonia (LOPES; MACEDO, 2011, p. 256).

Com base nesta definição percebemos que o contexto de influências está submetido a um jogo de disputas macroestruturais nacionais e globais (ALMEIDA; SANTIAGO; LEITE, 2013), envolvendo diversos atores que disputam espaço e poder, sendo então marcado pelos mais variados discursos que se interpelam na busca de tentar instituir suas concepções ideológicas na escola, visando avanços para a instituição ou apenas garantindo seus interesses próprios.

Um outro contexto evidenciado por Ball; Mainardes (2011) no Ciclo de Políticas diz respeito ao contexto do texto, que sendo um texto coletivo, "é produto de acordos realizados em diferentes esferas, envolvendo, inclusive, a troca constante de sujeitos autores" (LOPES; MACEDO, 2011, p.258). Vale salientar que o contexto do texto, embora fixado através da escrita e da formalização - como as políticas de currículo e avaliação amplamente divulgadas -, é passivo de interpretação e de ressignificação por parte dos sujeitos que o leem. Isto porque os sujeitos são influenciados pelas experiências diversas com as quais se depararam ao longo da vida, o que faz com interpretem os textos de formas diferenciadas, evidenciando assim, que os sentidos presentes no contexto do texto não são fixos, mas, modificáveis a cada leitura.

Por fim, trazemos à discussão o contexto da prática, para onde são pensadas e destinadas as políticas educacionais. É neste contexto que as políticas são recriadas e continuam a sofrer influência de outros atores, desta vez, os do cotidiano. Salientamos que esses contextos não se efetivam isoladamente, mas que perpassam um no outro e através de uma relação dialógica tencionam-se sobretudo no contexto da prática, onde as influências não se encerram, pois permanecem em constante movimento. Devido a isto é que Lopes e Macedo (2011) afirmam que "o contexto da prática é produtivo, mas não pode ser entendido fora dos constrangimentos estabelecidos pelas relações de poder reestruturadas, redistribuídas e recriadas pelas políticas (2011, p. 260), reforçando a ideia de que no contexto da prática as políticas e as influências que elas trazem consigo estão presentes e continuam a fazer parte de um jogo de disputas e interesses.

Para compreendermos melhor este movimento, trazemos à discussão, agora nas palavras de Ball, algumas considerações sobre o processo de criação das políticas nacionais:
A criação das políticas nacionais é, inevitavelmente, um processo de "bricolagem"; um constante processo de empréstimo e cópia de fragmentos e partes de ideias de outros contextos, de uso e melhoria das abordagens locais já tentadas e testadas, de teorias canibalizadoras, de investigação, de adoção de tendências e modas e, por vezes, de investimento em tudo aquilo que possa vir a funcionar. A maior parte das políticas são frágeis, produto de acordos, algo que pode ou não funcionar; elas são retrabalhadas, aperfeiçoadas, ensaiadas, crivadas de nuances e moduladas através de complexos processos de influência, produção e disseminação de textos e, em última análise, recriadas nos contextos da prática (BALL, 2001, p. 102).

Frente a todo este movimento que perpassa as políticas em seus variados contextos, percebemos que o contexto da prática exerce uma influência não menos significativa do que as influências presentes nas discussões políticas e nas formulações do texto político, mostrando que as políticas, ao entrarem em contato com inúmeros sujeitos e, entre estes, os sujeitos do contexto escolar, passam por modificações diversas.

Desse modo, as influências políticas presentes no contexto da prática influenciam a construção de identidades dos professores e o desenvolvimento da profissionalidade e profissionalismo dos mesmos, incidindo sobre o direcionamento de suas práticas e profissionalização (GONÇALVES; ALMEIDA; LEITE, 2018), isto porque "as mudanças nos contextos políticos e sociais do ensino têm tido implicações substantivas nas subjetividades dos professores" (FLORES, 2014, p. 863), contribuindo para os modos de ser e estar na profissão.

Vale salientar ainda que as políticas se apresentam enquanto fator de influência na constituição e desenvolvimento da profissionalidade e do profissionalismo não meramente pelo fato de direcionarem o que os professores precisam fazer - qual currículo espera-se que sigam, que tipo de avaliação espera-se que desenvolvam -, mas também, por se apresentarem no contexto da prática enquanto inacabadas e sujeitas à interpretação. Nesse sentido, as políticas educacionais, curriculares e de avaliação, por não serem um produto a ser consumido 
pelos professores, os desafia a fazer suas próprias análises acerca do que está sendo proposto, fazendo-os não somente refletir sobre as demandas de suas salas de aula e o possível atendimento dessas demandas (ou não) através das políticas que adentram a escola.

Por essa via de entendimento, Sacristán (1999) argumenta que os professores não definem a prática, mas sim o papel que ocupam enquanto profissional, o que nos leva a entender que através de sua atuação, os professores difundem, concretizam e também reconfiguram as múltiplas determinações provenientes dos contextos que integram. Deste modo, o autor ainda salienta que a conduta profissional dos professores

[...] pode ser uma simples adaptação às condições e requisitos impostos pelos contextos preestabelecidos, mas pode também assumir uma perspectiva crítica, estimulando o seu pensamento e a sua capacidade para adotar decisões estratégicas inteligentes para intervir nos contextos (1999, p. 74).

Os professores ao assumirem esta perspectiva crítica utilizam-se de saberes profissionais que os habilitam a agir em seus contextos de forma intencional e dirigida às necessidades de aprendizagem dos alunos. Deste modo, podemos considerar que mesmo as políticas que não são consideradas ideais para a demanda das escolas, possibilitam ao professor (ao adotar uma perspectiva crítica) o desenvolvimento profissional, visto que elas estimulam um exercício de análise e avaliação. Apesar disso, coadunamos com Flores (2014) que afirma que para além do mero questionamento das políticas e do modo como elas tentam ser implementadas na escola, faz-se necessário "analisar a forma como elas têm afetado o trabalho das escolas e dos professores, e fundamentalmente o modo como o seu profissionalismo tem sido (re) definido" (FLORES, 2014, p. 864).

Nessa lógica, ao procurarmos estabelecer relações entre o contexto das políticas e o contexto das práticas, partimos da compreensão de que embora as políticas influenciem nesse contexto, elas também sofrem influências que advêm da profissionalidade e do profissionalismo dos docentes, visto que essas dimensões não produzem efeitos e influências restritas à sala de aula, pois, nos afirma Alarcão (2001, p.23),

[...] a profissionalidade docente envolve dimensões que ultrapassam a mera dimensão pedagógica. Como ator social, o professor tem um papel a desempenhar na política educativa. No seio da escola, sua atividade desenrola-se no cruzamento das interações políticoadministrativo-curricular-pedagógicas.

Essa compreensão da profissionalidade - que está imbricada à de profissionalismo, enquanto dimensões que ultrapassam a dimensão pedagógica para desempenhar influências nos contextos das políticas educativas -, aponta para o fato de que nas salas de aulas, espaços em que se tecem as relações e práticas cotidianas, ocorrem movimentos de criação e recriação que desvencilham-se da mesmice comumente associada ao cotidiano e evidenciam que através dessas práticas, os professores podem ir além não apenas no que concerne ao seu saber-fazer e ao seu poder-fazer, mas também no que concerne a contextos considerados mais amplos e que, embora fisicamente os professores não estejam presentes ocupando um espaço ou fazendo ser ouvida sua voz nesses contextos, eles o fazem através de um plano discursivo, que não se limita a sua fala, mas que amplia e potencializa sua influência através das práticas que realiza em seu contexto micro de atuação.

\section{Algumas CONSIDERAÇões}

Considerando a diversidade de sujeitos que atuam na docência e as distinções profissionais existentes no grupo, concluímos ser pertinente a discussão da profissionalidade e do profissionalismo dos professores sob a perspectiva de não homogeneidade, o que agrega a estes conceitos um caráter polissêmico, à medida que ao falar de profissionalidade e de profissionalismo nos reportamos, simultaneamente, a uma diversidade de sujeitos e de identidades profissionais.

Levando em consideração o caráter processual da formação do próprio conceito de profissionalidade e de profissionalismo, enquanto dimensões de um processo mais amplo que se dá concomitantemente em nível individual e coletivo, ou seja, a profissionalização, objetivamos através deste trabalho analisar os contextos que influenciam no desenvolvimento da profissionalidade e do profissionalismo dos professores, na intenção de enfatizar algumas das possíveis variáveis que atestam a natureza de heterogeneidade e constante reformulação que estas dimensões profissionais possuem.

Nesse sentido, consideramos que a profissionalidade e o profissionalismo dos professores, em suma, seu saberfazer e seu poder-fazer, são delineados por fatores que estão atrelados à própria profissionalização em nível individual-coletivo, como por exemplo, a formação inicial (e acrescentaríamos ainda, a formação continuada) dos professores. Em nossas análises sobre a literatura especializada demos ênfase principalmente ao contexto histórico em que os professores se inserem, e que, por sua vez, delineia não só a profissionalidade enquanto prática, mas também enquanto conceito que está em constante reformulação de seus sentidos.

Também destacamos as condições de trabalho dos professores, apontando a forte associação entre os 
elementos físicos, materiais e relacionais, e a construção das práticas profissionais que levam ao desenvolvimento de profissionalidades e profissionalismos específicos, visto que o ambiente é determinante para a construção da ideia de pertencimento a nível material (lugar) e abstrato (profissão). Também demos ênfase às identidades profissionais, considerando-as em sua imbricação com as identidades pessoais, o que apresenta às histórias de vida e à pessoalidade dos sujeitos enquanto elementos fundantes no delineamento da profissionalidade e do profissionalismo dos sujeitos.

Por fim, mas sem a intenção de esgotar os elementos que influenciam na construção profissional dos sujeitos (visto que reconhecemos existirem outros elementos que possam, em diferentes contextos e épocas se agregarem a análise teórica que realizamos), destacamos os contextos políticos como sendo não só influenciadores, mas também desafiadores do desenvolvimento profissional, ao passo que exigem dos professores uma visão crítica, embasada por saberes específicos, que se consolidam nas influências que estes sujeitos produzem sobre o campo de criação das políticas na perspectiva de Ball (2001).

Em suma, dada a diversidade de elementos elencados e suas variadas atuações em diferentes contextos e sujeitos, finalizamos este texto enfatizando não haver um desenvolvimento único do que aqui conceituamos por profissionalidade e profissionalismo, como também não há fórmula única que guie o desenvolvimento profissional dos professores pois, uma vez que as influências a que os sujeitos estão expostos não podem ser medidas/ controladas, as formas e a intensidade com que os professores internalizam estas influências também não podem ser categorizadas uniformemente.

Assim, coube-nos enfatizar que a profissionalidade e o profissionalismo não se desenvolvem de modo padronizado, uma vez que, embora os currículos de formação de professores intentem uma massificação do que simboliza ser professor, cada sujeito desenvolve, em sua trajetória e em sua prática profissional, pontos de fuga, sentidos outros que emergem das subjetividades diversas e que forjam, em última instância, uma dinamicidade individual-profissional no processo de desenvolvimento da profissionalidade e do profissionalismo.

\section{REFERÊNCIAS}

ALARCÃO, Isabel. Escola reflexiva e nova racionalidade. Porto Alegre: Artmed, 2001.

ALMEIDA, L. A. A.; SANTIAGO, M. E.; LEITE, C. Um olhar sobre as políticas curriculares para formação de professores no Brasil e em Portugal na transição do século XX para o XXI. Revista Lusófona de Educação, Lisboa, v. 23, n. 23, p. 119-135, 2013.
ALVES, Cristovam da Silva; ANDRÉ, Marli Eliza Dalmazo Afonso de. A constituição da profissionalidade docente: os efeitos do campo de tensão do contexto escolar sobre os professores. In: REUNIÃO NACIONAL DA ASSOCIAÇÃO NACIONAL DE PÓS-GRADUAÇÃO E PESQUISA EM EDUCAÇ̃̃O, 36., 2013, Goiânia. Anais [...]. Goiânia: ANPED, 2013. p. 1-17.

BALL, Stephen J. Diretrizes Políticas Globais e Relações Políticas Locais em Educação. Currículo sem Fronteiras, Rio de Janeiro, v. 1, n. 2, p. 99-116, jul./dez. 2001.

BALL, Stephen J.; MAINARDES, Jefferson (org.). Políticas educacionais: questões e dilemas. São Paulo: Cortez, 2011.

BARISI, G. La notion de "profissionalitá" pur lês syndicats em Italei, L'Emploi enjeux économiques \& sociaux. Paris: Colloque de Dourdan, 1982. p.379-394.

BOING, Luiz Alberto. A Profissionalização Docente. In: Centro pedagógico Pedro Arrupe, 2002. Disponível em: https://www.google.com/url?sa=t\&rct=j\&q=\&esrc=s\& source $=$ web $\&$ cd $=10 \&$ cad $=$ rja \&uact $=8 \&$ ved $=2$ ahUKEwiVz vmvx8DfAhXEHpAKHfhdCFoQFjAJegQIBhAC\&url=http $\% 3 \mathrm{~A} \% 2 \mathrm{~F} \% 2 \mathrm{Fwww} 2$.fc.unesp.br\%2Feducacaoespecial $\% 2 \mathrm{~F}$ material $\% 2$ FSemana $\% 252004 \% 2 \mathrm{FA} \% 2520$ profissionaliza $\%$ 25E7\%25E3o\%2520docente.pdf\&usg=AOvVaw2_I0vqdhLsyxp3qOR7MS1. Acesso em: 27 dez. 2018.

CONTRERAS, José. Autonomia de professores. São Paulo: Cortez, 2002.

FLORES, Maria Assunção. Discursos do profissionalismo docente: paradoxos e alternativas conceptuais. Revista Brasileira de Educação, Rio de Janeiro, v. 19, n. 59, out./dez. 2014.

FREIDSON, Eliot. O renascimento do profissionalismo: teoria, profecia e política. São Paulo: Editora da Universidade de São Paulo, 1998.

GONÇALVES, Carlos M. Análise sociológica das profissões: principais eixos de desenvolvimento. Sociologia, Porto, v. 17, n. 1, p. 177-223, 2007.

Gonçalves, C. L.; ALMEIDA, L. A. A; LEITE, C. Práticas avaliativas e profissionalização nos cotidianos - uma análise de produções acadêmicas. Revista Teias, Rio de Janeiro, v. 19, n. 54, p. 209-225, 2018.

LOPES, Alice Casimiro; MACEDO, Elizabeth Macedo. Contribuições de Stephen Ball para o estudo de políticas de currículo. In: BALL, Stephen J.; MAINARDES, Jefferson (org.). Políticas educacionais: questões e dilemas. São Paulo: Cortez, 2011. p. 248-282

LÜDKE, Menga; BOING, Luiz Alberto. Caminhos da profissão e da profissionalidade docentes. Educação e Sociedade, Campinas, v. 25 , n. 89, p. 1159-1180, set./dez. 2004. Disponível em: http://www.cedes.unicamp.br. Acesso em: 12 dez. 2017. 
MONTEIRO, A. Reis. Profissão docente: profissionalidade e autorregulação. São Paulo: Cortez, 2015.

MORGADO, José Carlos. Identidade e profissionalidade docentes: sentidos e (im)possibilidades. Ensaio: aval. pol. públ. Educ., Rio de Janeiro, v. 19, n. 73, p.793-812, out./dez. 2011.

NÓVOA, António. Para uma formação de professores construída dentro da profissão. In: Professores: imagens do futuro presente. Lisboa: Educa, 2009. p. 25-46.

NÚÑEZ, Isauro Beltrán; RAMALHO, Betânia Leite. A profissionalização da docência: um olhar da representação de professores do ensino fundamental. Revista Ibero Americana de Educación, Araraquara, v. 46, n. 9, p. 1-13, set. 2008.

ORLANDI, Eni. Discurso e leitura. São Paulo: Cortez, 2012.

ORLANDI, Eni. Análise de discurso: princípios e procedimentos. Campinas: Pontes, 2005.

ROLDÃO, Maria do Céu Neves. Profissionalidade docente em análise: especificidades do ensino superior e não superior. Nuances: estudos sobre educação, Presidente Prudente, v. 12, n. 13, jan./dez. 2005.

ROLDÃO, Maria do Céu. Função docente: natureza e construção do conhecimento profissional. Revista Brasileira de Educação, Rio de Janeiro, v. 12, n. 34, p. 94-103, jan./abr. 2007.

SACRISTÁN, J. Gimeno. Consciência e ação sobre a prática como libertação profissional dos professores. In: NÓVOA, A. Profissão professor. Porto: Porto Editora, 1999. p. 63-92.

TARDIF, Maurice; LESSARD, Claude. O trabalho docente: elementos para uma teoria da docência como profissão de interações humanas. Petrópolis, RJ: Vozes. 2005.

VEIGA Ilma Passos Alencastro; CUNHA, Maria Isabel da. Desmistificando a profissionalização do magistério. Campinas: Papirus, 1999.

Recebido em: 19/1/2018.

Aprovado em: 27/12/2018.

Publicado em: 30/4/2019.

Endereço para correspondência:

Crislainy de Lira Gonçalves

I Trav. Mário Pederneira, 05 - Bairro Salgado

55018-561, Caruaru, PE, Brasil

Autores:

CRISLAiny de LiRa GonÇALVES

Mestre em Educação. Universidade Federal de Pernambuco (UFPE),

Caruaru, PE, Brasil.

Orcid: https://orcid.org/0000-0002-7612-294X

E-mail: crislainy67@gmail.com

Lucinalva Andrade Ataide de Almeida

Doutora em Educação. Universidade Federal de Pernambuco (UFPE),

Caruaru, PE, Brasil.

Orcid: https://orcid.org/0000-0002-3577-1716

E-mail: nina.ataide@gmail.com 